\title{
Construction of Cooperative Learning Network Mode under Adult Higher Education
}

\author{
Wu Mingxin ${ }^{1, a}$, Chu Ewei ${ }^{2, b}$ \\ ${ }^{1}$ College of continuing education, Beihang University, Beijing, 100191, China \\ ${ }^{2}$ Great Wall Computer Software\&Systems Inc, Beijing,100190, China \\ awmx@buaa.edu.cn \\ bchuwei@gwssi.com.cn
}

Keywords: Adult education; cooperative learning; network mode; construction

\begin{abstract}
This paper regards adult cooperative learning under the network environment as the research object, constructs a cooperative learning network mode under adult higher education, and discusses learning effect of applying cooperative principle into online network English learning for adults, by distributing questionnaire survey on the experimental class and control class, respectively, before and after testing, and analysis of students' online data. The result shows that theory and method of cooperative learning conform to characteristics of adult learners. Such a method not only contributes to improving learning initiative and helps a lot in improving teaching quality and building better learning atmosphere, but also can partially relieve life and work stress of students and solve influences of contraction between working and learning on study.
\end{abstract}

\section{Introduction}

With the development of computer multimedia technology and network technique, the chalk-blackboard pattern in traditional classroom teaching is gradually replaced by computer-assisted instruction. Multimedia network instruction has already been ascendant in English teaching. A lot of teaching experiments show that network resources have richness and effective interaction and are beneficial to improving classroom teaching efficiency. Therefore, based on the study of multiple learning models and methods of multimedia technology networks, now it has already been a focus generally concerned by current days. However, multimedia teaching has its own limitations. Its interaction mainly carries out among teachers, students and computers, while cooperation and exchange between people that has an important role on language teaching seems helpless. If this teaching pattern can combine with cooperative teaching, it can make up some shortcomings of computer-assisted instruction. This paper regards adult cooperative learning in network environment as the research object, and discusses learning effect of applying cooperative principle to adult online network English learning by using respective questionnaires and before and after tests in experimental class and control class, as well as analyzing network online data of students, etc., experimental methods.

\section{Mode Construction of Adult Cooperative Learning Strategy in Network Environment}

Cooperaitve Learning.

Adult cooperative learning strategy in network environment refers to a learning style that uses convenience of online information transfer to provide common learning activities for learners. In this pattern, learners are learning subjects. Teachers are partners and instructos. In learning process, learners exchange learning independently with learning partners in accordance with their demands and possibiliteis. In learning, when learners encounter with problems, they can discuss and common solve with learning partners on the internet. Expect for answering questions, sometimes teachers also can guide discussion, participate in debates, observe learning stuats of learners, and conduct individual coaching in necessity. 


\section{Characteristics of Adult Cooperative Learning in Network Environment}

As shown in Figure 1, learning in network environment is independent of limitations of time, place and space. Network platform provides abundant and colorful learning environment for cooperative learning. This environment is beneficial to motivate students' learning interest and learning efficiency. In network environment, adult learners are more convenient for selecting learning time and learning partners to discuss, negotiate and cooperate, overcome negative factors generalted by an isolated learning individuals, so as to be benefiical to improve learning efficiency.

In adult cooprative learning process, adult learners form abundant and colorful interpersonnal relationship network. This makes learning and association become an individsible entirety. Network creates a more free, flexible and open learning environment for learners by virtue of limitations across time and space. Network learning community is a learning organization for interaction, exchange and cooperation commonly consituted by different types of learners and counsellors. Collective responsibility of learners plays an important role on cooperative learning on learning community. When conducting cooperative learning on the Internet, learners can establish an equal relation in communication, encourage mutually, and build up network virtual learning area, so as to build a good learning atmosphere. Meantime, learning opportunities and learning resoruces obtained by learners are equal. In adult cooperative learning process of network environment, every adult learner is an independent and autonomous individual with development potential and has different life experience and diverse knowledge background. Therefore, different knowledge and meaning construction are existed in learning process.

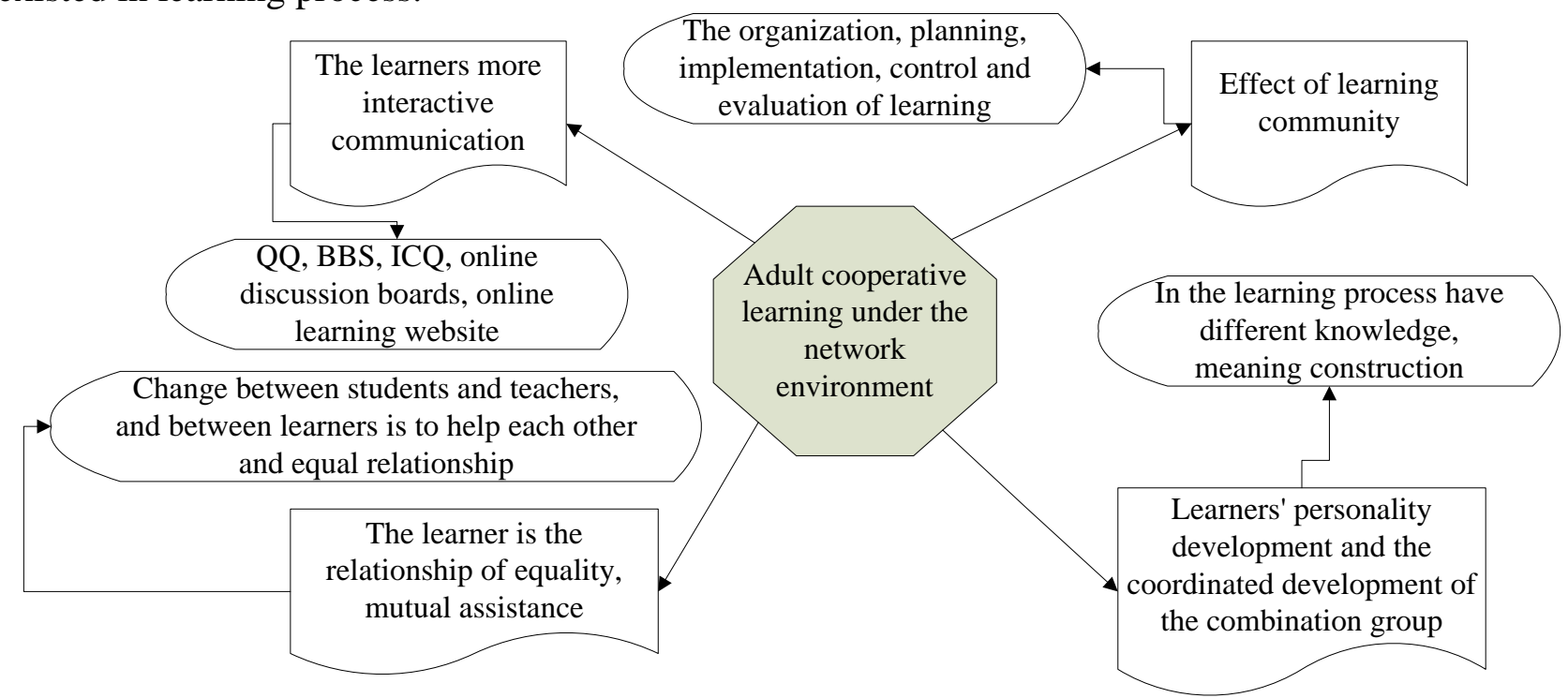

Figure 1 Cooperative Learning Characteristics in Network Environment

\section{Adult Cooperative Learning Pattern and Element Analysis in Network Environment}

As shown in Figure 2, elements of cooperative learning include students, teachers, learning contents, and learning environment. Cooperative learning in network environment considers network learning resources and network learning platform as learning means. Therefore, components of adult cooperative learning in network environment reorganize elements of independent study to some extent, due to dependency on specific learning environment, while indicating stability of basic elements, take full advantage of learning environment with interactive mechanism and abundant resources provided by computer network to realize a kind comprehensive learning style and inject new elements into basic elements. 


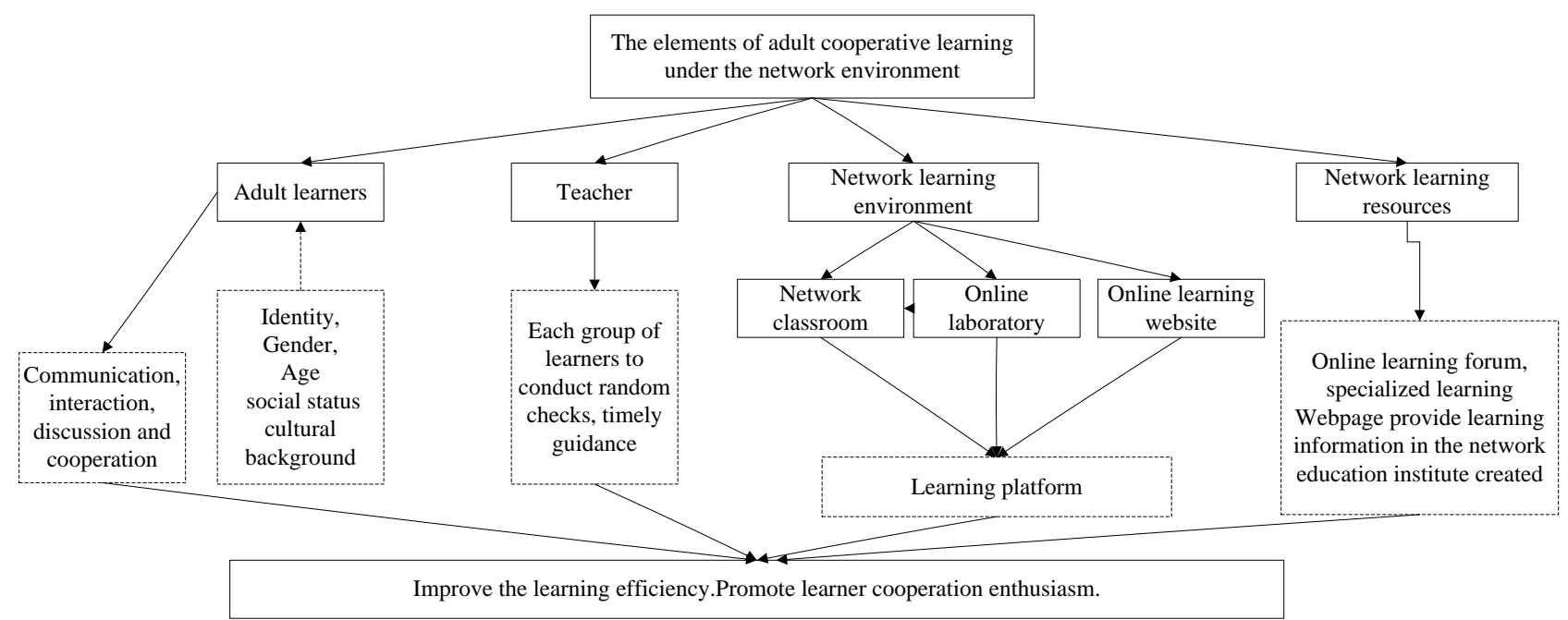

Figure 2 Components of Adult Cooperative Learning in Network Environment

As shown in Figure 3, a cooperative model concerning adult higher education in network is established in this paper. This model is teacher-centered, gives priority to teacher teaching and thinks that learning process is "speaking-listening". Based on network environment, adult learners should have stronger independent consciousness and learning ability. What's more, they should have cooperative learning consciousness and positive team learning consciousness. In this way, it can better develop their respective advantages and carry out effective cooperative learning. During the study period of cooperative groups, one of the methods of constructing individual responsibility consciousness and encouraging understanding is to supervise mutually. Learners can make use of allocated roles to realize individual responsibility consciousness. Adult learners who are specified roles will have more distinct expectation on individual responsibility. Cooperative learning tasks between group members are related to existing learning, work experience, life background, existing knowledge structure, and required learning objectives. Constructing a good learning service support system will provide powerful support and safeguard for learners who conduct cooperative learning. In this way, it can effectively promote adult adults to carry out cooperative learning. In network environment, learning service support is one of pillars of network learning.

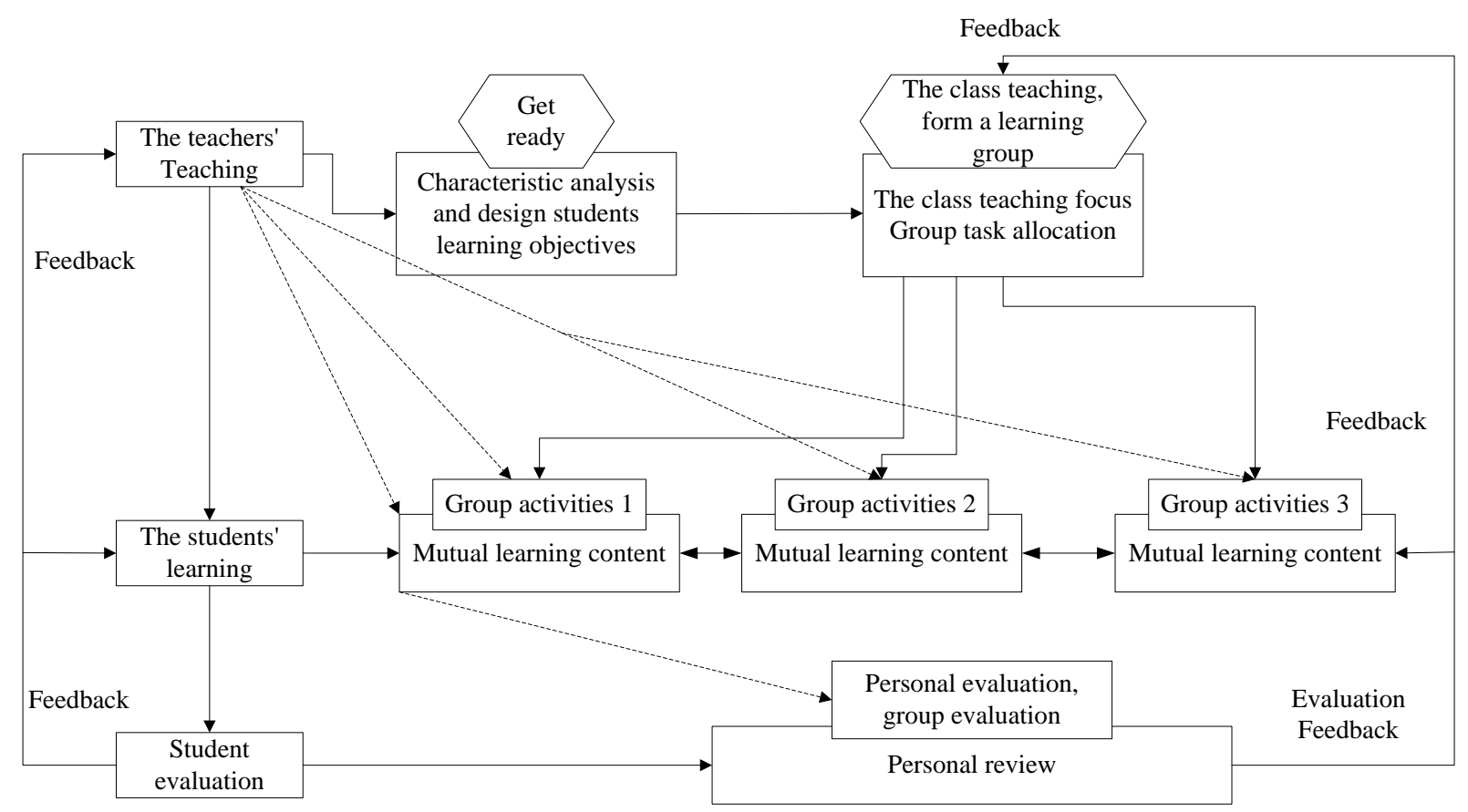

Figure 3 Cooperative Learning Network Pattern of Adult Higher Education 


\section{Reinforcement Learning Reliability Distribution of Adult Education Cooperative Multi-Agent System in Network Environment}

In general cooperative multi-agent system, every multi-agent system may play a different role. The learning effect is also different. Therefore, it is impossible to maintain the same reward in such a situation. For reinforcement learning of the general cooperative multi-agent system, the barrier of gaining EIR reward is because that individual reward EIR, as a kind of reliability distribution way, has unknown other intelligent-agent strategies and united rewards.

$$
r\left(s, a^{i}\right)=\sum_{a^{1} \in A^{1}} \ldots \sum_{a^{t-1} \in A^{t-1}} \sum_{a^{t+1} \in A^{t+1}} \ldots \sum_{a^{N} \in A^{N}} \prod_{j=1, j \neq i}^{N} \pi_{*}^{j}\left(a^{j} \mid s\right) r(s, a)
$$

In learning intelligent-agent/united state $S$, behaviors and actions of other intelligent-agent systems are observed. Moreover, it notes $\pi\left(a^{j} \mid s\right)$ as the predicted strategy of learning intelligent-agent system for partner intelligent-agent system, namely in united state, the probability that intelligent-agent system j can execute action $a^{j}$ obviously has:

$$
\sum_{a^{j} \in A^{i}}\left(a^{j} \mid s\right)=1, \mathrm{j}=1,2, \ldots, \mathrm{i}-1, \mathrm{i}+1, \ldots, \mathrm{N}
$$

In order to reduce complexity of calculation for spate storage, we adopt Robin-Monro method to predict strategies of other intelligent-agent systems. At time t, when intelligent-agent systems observe executive action $a_{t}^{j}\left(a_{t}^{j} \in A^{j}, j \neq i\right)$ of the intelligent-agent $\mathrm{j}$, we should apply the following way to update its strategies.

$$
\bar{\pi}_{t+1}^{j}\left(a^{j} \mid s\right)=\left(1-u_{t}^{j}\right) \bar{\pi}_{t+1}^{j}\left(a^{j} \mid s\right)+ \begin{cases}u_{t}^{j} & \text { if } \quad a^{j}=a_{t}^{j} \\ 0 & \text { otherwise }\end{cases}
$$

Here $\bar{\pi}_{t+1}^{j}\left(a^{j} \mid s\right)$ refers to strategy update after intelligent-agent system j executes action at time t. $u_{t}^{j}(0<\mathrm{u}<1)$ refers to updated learning rate. This sequence $u_{t}^{j}$ satisfies the following conditions.

$$
\sum_{t=0}^{\infty} u_{t}^{j}=\propto, \sum_{t=0}^{\infty}\left(u_{t}^{j}\right)^{2}<\propto
$$

Let $\mathrm{t} \rightarrow \infty$, there is $\bar{\pi}_{t+1}^{j}\left(a^{j} \mid s\right) \rightarrow \pi_{t+1}^{j}\left(a^{j} \mid s\right)$

\section{Research Result Analysis of Adult Education Cooperative Learning Model in Network Environment}

I use SPSS19.0 to conduct statistic analysis. Because variable of this investigation is discrete variable, when testing different age groups, namely 20 years old, 30 years old and 40 years old and evaluating cooperative learning's significance of data difference on English level, it applies nonparametric and independent multiple samples to test.

As shown in Table 1, according to the result of SPSs, initial test performance of experimental class (namely students of administrative management major) has the mean value of 65.44(full mark 100 points). Initial test performance of control group (namely business administration major) has the mean value of 66.72 . Sig (20tailed) $=0.305>0.05$. The data display that two groups have no significant difference in English learning ability and level. Initial English level of two classes is similar. 
Table 1 Independent Sample Test

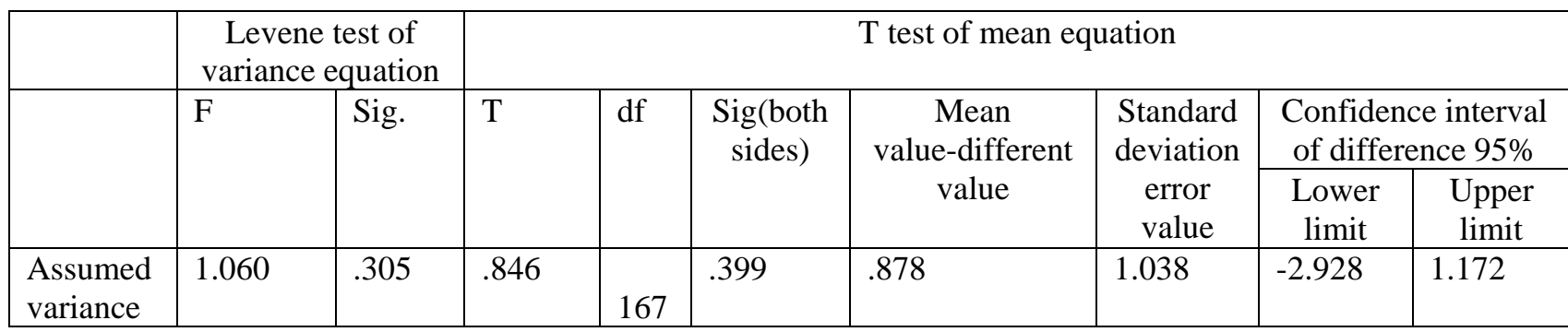

As shown in Table 2, mean value before and after testing are 65.44 and 69.44, respectively. The result shows that average scores in experimental class before and after testing differ 4 points. Term end increases by $6.1 \%$ than initial term, and $\mathrm{T}$ test $\mathrm{SIG}(2$-tailed $)=0.000<0.05$. It indicates that mean value in experimental class before and after testing has significant difference. By longitudinal comparison, it indicates that after experimental class uses network online English cooperative learning, average scores make an obvious progress by comparing with initial scores in experimental class. It proves that cooperative learning can effectively improve adult English learning performance.

Table 2 Pairing Sample Testing

\begin{tabular}{|c|l|l|l|l|l|l|l|l|}
\hline & \multicolumn{9}{|c|}{} & \multicolumn{5}{|c|}{ Pairing difference } \\
\hline & $\mathrm{T}$ & df & $\begin{array}{c}\text { Sig(both } \\
\text { sides) }\end{array}$ & $\begin{array}{c}\text { Mean } \\
\text { value }\end{array}$ & $\begin{array}{c}\text { Standard } \\
\text { deviation }\end{array}$ & $\begin{array}{c}\text { Standard deviation } \\
\text { error value }\end{array}$ & \multicolumn{2}{c|}{$\begin{array}{c}\text { Confidence interval } \\
\text { of difference 95\% }\end{array}$} \\
\cline { 4 - 8 } & & & & & & $\begin{array}{c}\text { Lower } \\
\text { limit }\end{array}$ & $\begin{array}{c}\text { Upper } \\
\text { limit }\end{array}$ \\
\hline $\begin{array}{c}\text { Comparison } \\
1 \text { before - } \\
\text { after }\end{array}$ & -9.473 & 86 & 0 & 4.000 & 3.938 & .422 & -4.839 & -3.161 \\
\end{tabular}

As shown in Table 3, performance of other parts improves slightly (according to the order in the table, including $0.147,-0.522,0.629,0.222,0.407$ and 1.037 , respectively). Particularly, writing makes an obvious progress (before testing, it is 12.074, after testing, it is 13.111, and it increases by 1.037 points). It can be observed from pre-testing performance that adult learners at 20 years old have good English foundation. Vocabulary is obviously more than learners at other ages. In addition, cooperative learning can provide writing framework and idea for them. Therefore, their writing progress is very obvious. This is consistent with previous result, but it is opposite to previous questionnaire. Through the evaluation on sentence pattern and language point for learners at this age is higher than other aspects, term end performance shows that vocabulary and structure division, namely specialized check grammar sentence pattern go down correspondingly, because students may pay a little attention on this section, and pre-revision is incomprehensive.

Table 3 Score Data at 20 Years Old

\begin{tabular}{|c|c|c|c|c|c|c|c|c|}
\hline & & $\begin{array}{c}\text { Communcit } \\
\text { ation }\end{array}$ & $\begin{array}{l}\text { Vocabular } \\
\text { y and } \\
\text { structure }\end{array}$ & $\begin{array}{c}\text { Cloze } \\
\text { test }\end{array}$ & $\begin{array}{c}\text { Reading } \\
\text { comprehesion }\end{array}$ & $\begin{array}{l}\text { Translation } \\
\text { from } \\
\text { English } \\
\text { into } \\
\text { Chinese }\end{array}$ & $\begin{array}{c}\text { Writing } \\
\text { expression }\end{array}$ & $\begin{array}{c}\text { Total } \\
\text { points }\end{array}$ \\
\hline \multirow{2}{*}{$\begin{array}{c}\text { Pre-tes } \\
\text { ting } \\
\text { perfor } \\
\text { mance } \\
\text { 27peop } \\
\text { le }\end{array}$} & $\begin{array}{l}\text { Mean } \\
\text { value }\end{array}$ & 7.778 & 13.963 & 5.482 & 18.222 & 8.667 & 12.074 & 66.70 \\
\hline & $\begin{array}{l}\text { Standard } \\
\text { deviation }\end{array}$ & 1.013 & 2.009 & 1.282 & 3.651 & 3.270 & 0.917 & 4.898 \\
\hline \multirow{2}{*}{$\begin{array}{c}\text { Post-te } \\
\text { sting } \\
\text { perfor } \\
\text { mance } \\
27 \\
\text { people }\end{array}$} & $\begin{array}{l}\text { Mean } \\
\text { value }\end{array}$ & 7.925 & 13.441 & 6.111 & 18.444 & 9.074 & 13.111 & 69.81 \\
\hline & $\begin{array}{l}\text { Standard } \\
\text { deviation }\end{array}$ & 1.616 & 2.698 & 1.553 & 3.609 & 2.759 & 0.934 & 4.472 \\
\hline
\end{tabular}


As shown in Table 4, test performance of learners at 30 years old is inferior to learners at 20 years old (65.18:66.70), but progress range is greater than learners at 20 years old(improved 6.60\%:4.67\%). Meanwhile, it can be observed from the above table, adult learners at this age make an obvious progress in vocabulary and structure and reading comprehension (improved $19.28 \%$ and 9.54\%, respectively). It shows that network English cooperative learning for one semester has significant effects on improving their basic grammar and reading comprehension. Learners at this age are better at consolidating learned grammar in repeated discussion and improving their English reading ability imperceptibly. Though they don't have high evaluation on memorizing words and translation competence in previous in previous questionnaire, in term end examination, translation on from English into Chinese and writing expression exceed the border line. It indicates that cooperative learning promotes these two aspects.

Table 4 Score Data at 30 Years Old

\begin{tabular}{|c|c|c|c|c|c|c|c|c|}
\hline & & $\begin{array}{l}\text { Commu } \\
\text { ncitatio } \\
\mathrm{n}\end{array}$ & $\begin{array}{l}\text { Vocabulary } \\
\text { and structure }\end{array}$ & $\begin{array}{l}\text { Cloze } \\
\text { test }\end{array}$ & $\begin{array}{l}\text { Reading } \\
\text { comprehe } \\
\text { sion }\end{array}$ & $\begin{array}{l}\text { Translatio } \\
\text { n from } \\
\text { English } \\
\text { into } \\
\text { Chinese }\end{array}$ & $\begin{array}{l}\text { Writing } \\
\text { expression }\end{array}$ & Total \\
\hline \multirow{2}{*}{$\begin{array}{l}\text { Pre-testing } \\
\text { performance } \\
\text { 57people }\end{array}$} & $\begin{array}{l}\text { Mean } \\
\text { value }\end{array}$ & 6.734 & 12.825 & 4.684 & 19.474 & 8.456 & 11.684 & 65.18 \\
\hline & $\begin{array}{l}\text { Standard } \\
\text { deviation }\end{array}$ & 1.798 & 2.700 & 1.454 & 3.690 & 3.180 & 1.490 & 5.346 \\
\hline \multirow{2}{*}{$\begin{array}{l}\text { Post-testing } \\
\text { performance } \\
57 \text { people }\end{array}$} & $\begin{array}{l}\text { Mean } \\
\text { value }\end{array}$ & 7.263 & 15.298 & 6.000 & 21.333 & 9.737 & 12.053 & 69.54 \\
\hline & $\begin{array}{l}\text { Standard } \\
\text { deviation }\end{array}$ & 1.876 & 2.379 & 1.680 & 3.174 & 3.021 & 1.481 & 4.885 \\
\hline
\end{tabular}

Only 3 people at 40 years old don't have great difference between before and after scores. Except for a person who makes a great progress, the other two people don't have significant difference. It may be English level of these three people is weaker. It is not proficient for them to participate in online discussion. I should pay more attention to this cooperative group.

The left figure in Figure 4 indicates that status motion of $<14,8,0,4 \ldots \pi / 2\rangle$ is corresponding to approximate process of EIR. At the earlier time of EIR approach, because state $<14,8>$ function, EDR doesn't constrict completely. Learning intelligent-agent system has larger probability to explore, so EIR's approach fluctuation is larger. With the increase of iterations, EIR's ultimate convergence is close to constant 10. It means that if a partner adopts the optimal strategy, learning intelligent-agent system can reach target state after adopting corresponding action in state $<14,8>$. Ultimately, convergence of state motion function $(4,8,0.4, \pi / 2)$ in optimal corresponding algorithm learning, it approaches 10. It indicates that the proposed EIR is close to the effectiveness of strategy. In conclusion, in MARL-TT algorithm, intelligent-agent system realizes better reliability distribution. By alternating tracking framework, alternative learning of intelligent-agent system can obtain the optimal responding strategy of other intelligent-agent system. Form the entire perspective, it can be regarded as a onlooker, while learning. 

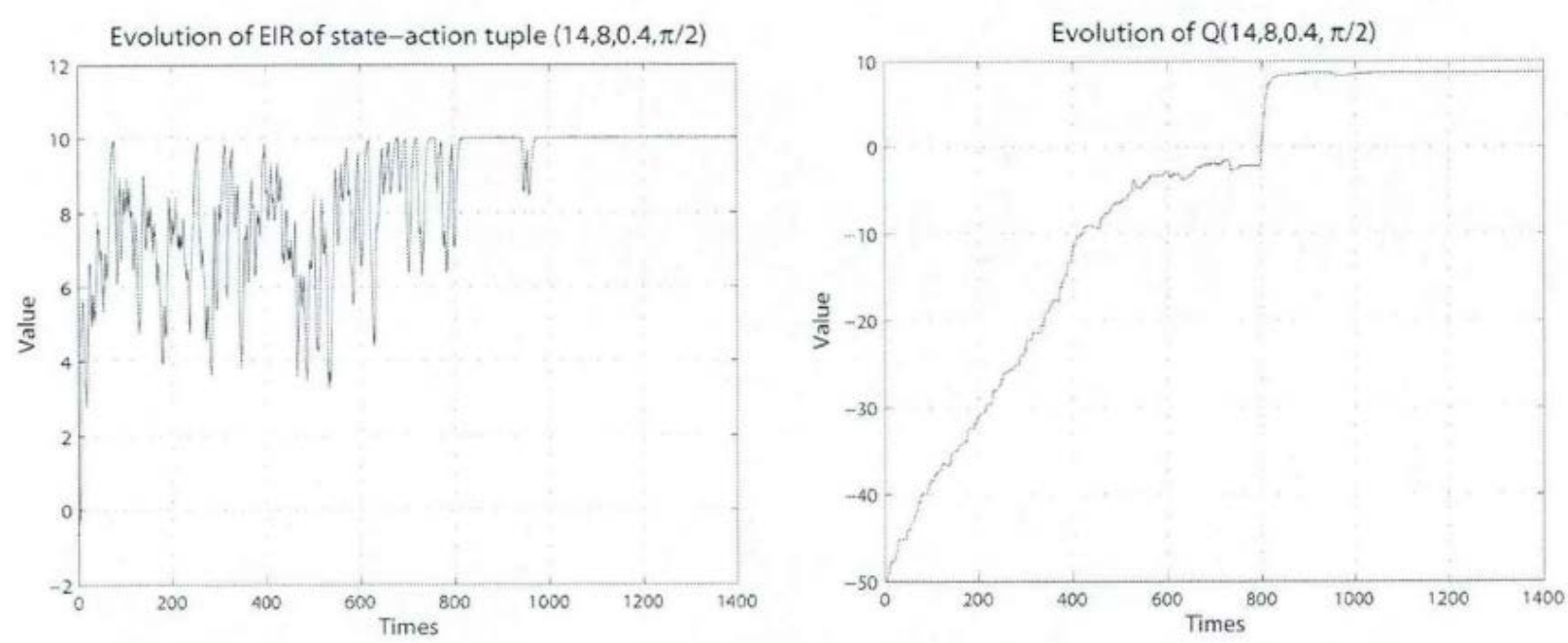

Figure 4 Sampling Tracking of Certain United State Independent Action on EIR and Q Value Evolution

\section{Summary}

For adult online network English cooperative learning, it is extremely necessary and effective to concentrate on each language point to carry out discussion and settle and summary right and wrong at staging. On the one hand, this can unite fragmentary impression and help students to understand problems better. On the other hand, it can provide concentrated learning materials for students, save learning time and improve learning efficiency. As for teachers, it is still necessary to explore constantly, spare no efforts to look for the balance among cooperative learning, adult education and online network learning, and try to give online cooperative learning activities. The Better teaching effect can be reached by evaluating learning situation of network students and online adult student performance and applying more reasonable teaching strategies.

\section{References}

[1] Wang Tan, Idea and Practice of Cooperative Learning, Beijing: Chinese Personnel Press, 2002, p16-25;

[2] Sheng Qunli and Zheng Shuzhen, Cooperative Learning Design, Hangzhou: Zhejiang Education Publishing Press, 2006, p8-45;

[3] Li Jun, Introduction to Network Education, Beijing: Tsinghua University Press, 2011, p6-108;

[4] Ji He, Adult Network Learning, Nanjing: Southeast University Press, 2010, p5-126;

[5] Gao Dandan, Discussion on Evaluation of Network Learning, Study on Electrified Education, 2009, Vol11, p27-31;

[6] Hui Fang, Discussion on Adult Cooperative Learning, Journal of Higher Correspondence Education, Philosophy and social science, 2011, Vol03, p27-29;

[7] Liu Xiufeng, Brief Introduction to Cooperative Learning Model in Network Environment, Teaching and management, 2007, Vol03, p74-75;

[8] Guo Wei and Sun Zhaolei, Exploration on Adult Cooperative Learning, Chinese Adult Education, 2012, Vol 01, p31-33;

[9] Liu Chao, Discussion on Implementation Strategy of Adult Cooperative Learning, Chinese Adult Education, 2009, Vol 19, p9-10;

[10] Sun Yanchao, Motivation Stimulating Strategy Study on Initial Stage of Adult Learning in Network Environment, Journal of Guangxi Radio and Television University, 2008, Vol. 01, p19-23. 